\title{
The use of Mixed-Income Housing Development to Address Poverty and Inequality, Based on Delphi Empirical Approach: A Case of South Africa
}

\author{
George Onatu', Vutivi Kay Baloyi ${ }^{2, *}$ \\ 1 Lecturer, University of Johannesburg \\ P O Box 17011 Doornfontein, 2028 Johannesburg, South Africa \\ ${ }^{2}$ Masters Candidate, University of Johannesburg \\ P O Box 17011 Doornfontein, 2028 Johannesburg, South Africa
}

\begin{abstract}
.
Since the dawn of democracy in 1994, the Republic of South Africa (RSA) has been trying to address the aftermath and consequences of the apartheid regime. This comprises of the socioeconomic, spatial, and political challenges that have persisted over the decades. These have had far reaching repercussions in the society to the extent that 25 years later after apartheid, the country finds itself with alarming rates of poverty, social exclusion, unemployment, and inequality. Literature has revealed that there is a direct relationship between poverty and inequality as well as access to socio-economic services / opportunities. Poor access to these services perpetuates exclusivity and thus inequality and marginalisation in all form and character.

The purpose of this study is to investigate how housing developments have been used in South Africa to address poverty and inequality. The aim is to understand how to plan for better and more socially and economically thriving communities through housing development, focusing specifically on aspects of development that contributes to addressing poverty and inequality. Using a Delphi three round method of Inquiry of 20 experts, perceptions from a diverse panel of experts about mixed-income housing development were uncovered. In comparison to previous housing models, the study uncovered a significant paradigm shift in housing development and what a housing intervention should achieve. Since 2004 after the introduction of the Breaking New Ground Policy (BNG), the housing development approaches, and interventions have shifted away from just providing roof over once head to providing social asset to the poor and a whole range economic opportunities. The conclusion is that housing development by virtue of location, diverse housing typologies and tenure options is now part and parcel of integrated planning and the pro poor development agenda.
\end{abstract}

Keywords: Access to services, poverty, inequality, integration, and mixed-income housing. 